\title{
Pengukuran Maturity Level Cobit 5 Dan Domain DSS (Deliver, Service, And Support) Pada Regulasi Sandbox OJK Klaster Aggregator
}

\author{
Nur Lelasari ${ }^{1}$, Candiwan ${ }^{2}$, Helni Mutiarsih Jumhur ${ }^{3}$, Maya Ariyanti ${ }^{4}$, Soeparwoto \\ Dharmoputra $^{5}$ \\ ${ }^{1,5}$ Universitas Telkom; Jalan Telekomunikasi, Terusan Buah Batu, Bandung 40257, \\ +62 22 7564108/+62 227565200 \\ 1,5 Jurusan Manajemen Bisinis Telekomunikasi dan Informatika, FEB Telkom, Bandung \\ e-mail: ${ }^{1}$ nurlelasari@student.telkomuniversity.ac.id, ${ }^{2}$ candiwan@telkomuniversity.ac.id, \\ ${ }^{3}$ helnimj@telkomuniversity.ac.id, ${ }^{4}$ ariyanti@telkomuniversity.ac.id, \\ ${ }^{5}$ soeparwoto@telkomuniversity.ac.id
}

\begin{abstract}
Abstrak
Dengan berkembangnya internet dan fintech yang begitu cepat, masyarakat memiliki permasalahan dalam pengambilan keputusan untuk memilihan layanan atau produk fintech yang tepat karena saat ini banyak layanan yang sama ditawarkan dengan berbagai aplikasi atau web service. Dengan demikian maka muncul layanan Inovasi Keuangan Digital (IKD) klaster aggregator pada Otoritas Jasa Keuangan (OJK) untuk dijadikan solusi dalam pengambilan keputusan yang lebih cepat dan tepat dengan melakukan comparasion sitelapplication. Agar produk finansial memiliki kepastian status dalam menjalankan usahanya, maka harus mengikuti tahapan pengujian Regulasi Sandbox. Penelitian ini menggunakan metode kualitatif. Hasil penelitian dianalisis menggunakan Maturity Level COBIT 5 dengan domain yang dipilih DSS (deliver, service, support) pada subdomain manage problem dan manage business process control. Hasil penelitian menunjukan bahwa klaster aggregator berdasarkan sampel yang dipilih telah sesuai dalam melaksanakan Regulasi Sandbox berdasarkan 5 tahapan. Hasil maturity level tahap pendalaman sebesar 4.2, tahap pengujian skenario sebesar 3, tahap pengujian dan percobaan sebesar 3.3, tahap perbaikan 3.2 serta tahap penilaian 2.9. Hasil maturity level domain manage problem sebesar 3.8 (4) artinya telah masuk dalam level predictable sedangkan domain manage business process control sebesar 3.3 (3) artinya telah masuk dalam level established.
\end{abstract}

Kata kunci-Regulasi Sandbox, Aggregator, Klaster, Fintech, Maturity Level.

\begin{abstract}
With the rapid development of the internet and fintech, people have problems in making decisions to choose the right fintech service or product because currently many of the same services are offered with various applications or web services. Thus, the aggregator cluster Digital Financial Innovation (IKD) service appears at the Financial Services Authority (OJK) to be used as a solution in making decisions that are faster and more precise by conducting site I application comparisons. In order for financial products to have a certain status in running their business, they must follow the Sandbox Regulation testing stages. This study uses a qualitative method. The results were analyzed using Maturity Level COBIT 5 with the DSS (deliver, service, support) selected domain in the sub-domain manage problems and manage business process control. The results showed that the aggregator cluster based on the selected sample was appropriate in implementing Sandbox Regulation based on 5 stages. The results of the maturity level for the deepening stage are 4.2, the scenario testing stage is 3, the testing and trial stage is 3.3, the improvement stage is 3.2 and the assessment stage is 2.9. The result of
\end{abstract}


maturity level domain manage problem is 3.8 (4), which means that it has entered the predictable level, while the domain manage business process control is 3.3 (3) which means it has entered the established level.

Keywords-Regulasi Sandbox, Aggregator, Cluster, Fintech, Maturity Level

\section{PENDAHULUAN}

Pada era digital perkembangan teknologi menjadi sangat pesat sehingga mempengaruhi manusia dalam mengakses beragam informasi termasuk akses teknologi finansial [1]. Teknologi financial yang terus mengalami perkembangan, akan mendukung pencapaian rencana utama pada sektor jasa keuangan hal ini dikarenakan mampu mendukung percepatan pertumbuhan ekonomi nasional, menjaga stabilitas sistem keuangan sebagai landasan pembangunan secara berkelanjutan serta meningkatkan kesejahteraan masyarakat melalui akses kemudahan layanan keuangan dengan berbagai layanan financial yang ditawarkan [2]. Pada gambar 1. menunjukan transaksi fintech di Indonesia terus mengalami kenaikan yang signifikan dari tahun 2015-2021 namun tantangan yang dihadapi bagi startup fintech tanah air yaitu banyaknya populasi penduduk namun masih belum mengenal teknologi finansial serta manfaat yang ditawarkan [3].

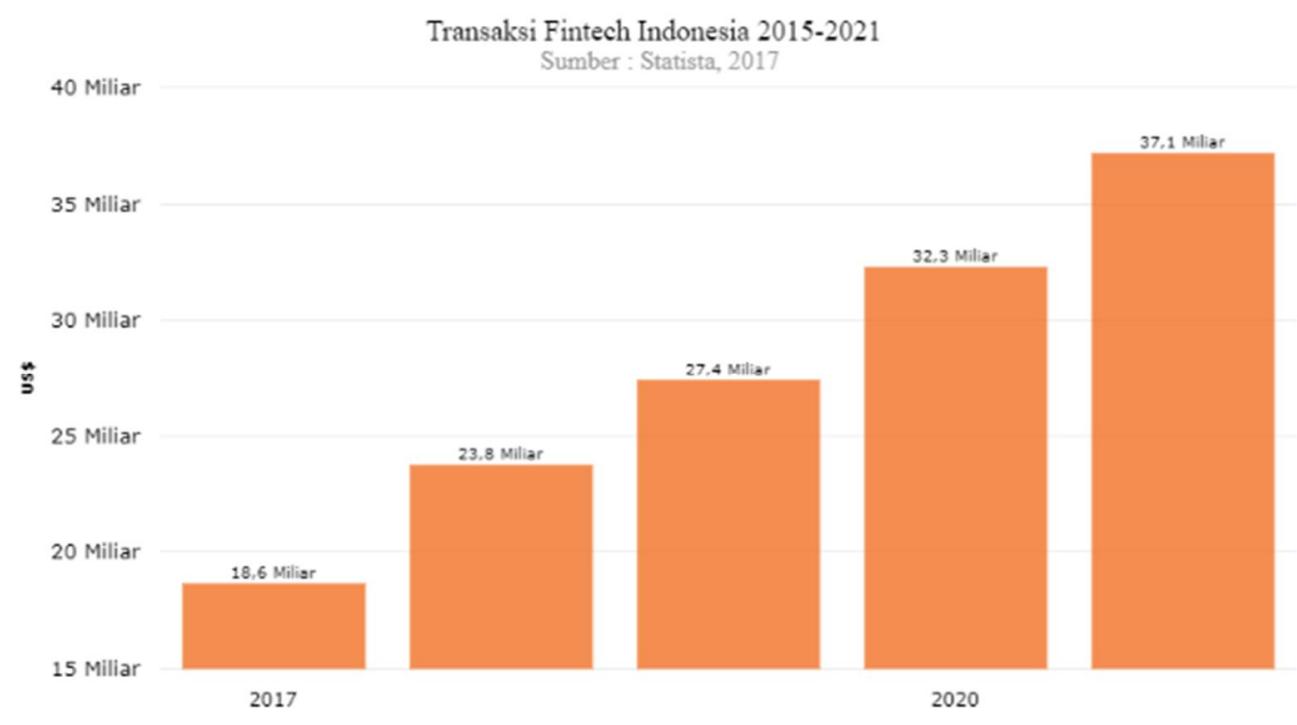

Gambar 1. Transaksi Fintech Indonesia 2015-2021

Perusahaan fintech yang terdaftar sebagai anggota Aftech terus meningkat hingga kuartal II tahun 2020, dimana beradasarkan empat kategori layanan finansial, pinjaman online menjadi paling dominan kemudian di ikuti oleh kategori Inovasi Keuangan Digital (IKD) [4].Salah satu produk dari Inovasi Keuangan Digital (IKD) adalah klaster aggregator. Aggregator lahir karena diera digitalisasi menciptakan banyaknya produk finansial yang berkembang sangat pesat di masyarakat sehingga masyarakat kesulitan dalam memilih produk yang sesuai sehingga dibutuhkan comparison site untuk membantu masyarakat dalam proses pengambilan keputusan dalam memilih layanan fintech [5].

Layanan fintech aggregator lahir karena penyelenggara melihat potensi pasar yang cukup besar terkait banyaknya produk fintech OJK yang semakin bertambah menjadikan suatu

Lelasari, et., al [Pengukuran Maturity Level Cobit 5 dan Domain DSS (Deliver, Service, and Support) pada Regulasi Sandbox OJK Klaster Aggregator] 
permasalahan konsumen kesulitan dalam memilih produk finansial terbaik untuk dijadikan proses pengambilan keputusan sehingga OJK menyiapkan layanan aggregator untuk memfasilitasi agar konsumen bisa mengambil keputusan terkait produk fintech yang terbaik [6]. Layanan fintech aggregator dapat digunakan untuk mengelola dan memberikan informasi layanan keuangan, melakukan perbandingan fitur, harga, layanan, serta manfaat yang ditawarkan dari perusahaan terkait sehingga berguna bagi konsumen untuk menentukan produk keuangan yang tepat [7].

Layanan fintech aggregator merupakan salah satu paling berkembang dari 16 klaster inovasi keuangan digital lainnya sehingga di perlukan regulasi agar tidak keluar dari ranahnya dan sesuai perizinan awal yang mengacu pada Regulasi Sandbox [8]. Regulasi Sandbox diselenggarakan untuk membuat suatu forum yang digunakan untuk mempertemukan para pelaku industri dengan regulator dengan tujuan melakukan pengidentifikasian dan observasi terkait risiko pada layanan jasa keuangan dan dinamika pasar dengan cara melakukan interpretasi terhadap model bisnis dan proses bisnis baru guna menjaga stabilitas sistem keuangan serta menentukan upaya mitigasi yang tepat [9]. Regulasi Sandbox dilaksanakan untuk mewujudkan platform klaster IKD termasuk aggregator yang memiliki izin berdasarkan lembaga yang berwenang atas pengawasan dan pemeriksaan keuangan di Indonesia [9]

Tujuan Regulasi Sandbox ini untuk menciptakan platform aggregator yang memberikan perlindungan bagi konsumen, bagi calon pengguna layanan tersebut agar tidak ada pihak yang dirugikan, serta memberikan kepastian status bagi penyelenggara fintech aggregator sehingga mampu menjalankan usahanya sesuai dengan peraturan lembaga jasa keuangan yang berlaku. [9].

\section{METODE PENELITIAN}

\subsection{Dasar Teori}

\section{1.1 Regulasi Sandbox}

SEOJK Nomor 21 (2019) menjelaskan Regulasi Sandbox adalah mekanisme pengujian yang dilakukan oleh Otoritas Jasa Keuangan berupa proses untuk menilai keandalan proses bisnis, model bisnis, instrumen keuangan, dan tata kelola penyelenggara dengan tujuan untuk mengidentifikasi jenis-jenis fintech yang belum teridentifikasi atau belum berizin dengan memenuhi kriteria inovasi keuangan digital berdasarkan 5 (lima) tahapan yaitu tahap pendalaman, tahap pengujian skenario, tahap pengujian dan percobaan, tahap perbaikan dan tahap penilaian. [10]. Peraturan Anggota Dewan Gubernur (2017) merupakan ruang uji coba yang memiliki beberapa prinsip diantaranya yaitu transparansi, keadilan (fairness), proposionalitas atau menyeimbangkan agar sesuai dengan tujuan yang akan dicapai, criteriabased process, kesetaraan (equal treatment) dan forward looking dimana digunakan untuk menguji penyelenggara fintech [11]. Goo dan Heo (2020) Regulasi Sandbox merupakan ruang uji coba untuk model bisnis baru, produk inovatif, service, dan mekanisme pengiriman dalam ruang pengujian yang aman serta memiliki pengaruh yang sangat positif pada pertumbuhan investasi fintech dan menghilangkan ketidakpastian peraturan. [12].

\section{1.2 Maturity Level}

Maturity Level adalah adalah gambaran tingkat kematangann teknologi informasi dalam suatu organisasi yang digunakan sebagai tolak ukur dan alat penilaian manajemen IT dalam menilai sejauh mana tingkat kematangan nya di implementasi [13]. Maturity Level digunakan untuk mengidentifikasi peningkatan prioritas dalam suatu organisasi yang hendak dilakukan serta meningkatkan kesadaran pentingnya pengelolaan proses teknologi informasi [14].

Lelasari, et., al [Pengukuran Maturity Level Cobit 5 dan Domain DSS (Deliver, Service, and Support) pada Regulasi Sandbox OJK Klaster Aggregator] 


\subsubsection{COBIT 5}

COBIT (Control Objectives for Information and Related Technology) merupakan pedoman yang digunakan untuk melakukan manajemen TI dibuat oleh Information Systems Audit and Control Association (ISACA) dan IT Governance Institute (ITGI) [15]. COBIT digunakan untuk memastikan penerapan teknologi informasi dapat mendukung tujuan serta goals yang ditetapkan suatu perusahaan dengan cara mengukur kualitas tatakelola teknologi informasi pada perusahaan terkait [16]. Domain yang dipilih pada penelitian ini pada domain deliver, service and support (DSS) untuk melakukan evaluasi layanan teknologi informasi dalam penerapan proses Regulasi Sandbox klaster aggregator untuk melakukan pengendalian bisnis jangka panjang serta melakukan evaluasi dan proses perencanaan [17].

Tabel 1. COBIT 5 Process Capability Model

\begin{tabular}{|c|l|l|}
\hline Level & Value & \multicolumn{1}{c|}{ Description } \\
\hline 0 & Incomplete & $\begin{array}{l}\text { (Proses tidak dilaksanakan/ tidak lengkap). } \\
\text { Pada level ini menunjukan bahwa proses nya tidak } \\
\text { dilaksanakan secara lengkap, tidak diimplementasikan atau } \\
\text { tisak sesuai dengan tujuan yang telah ditetapkan. }\end{array}$ \\
\hline 1 & Performend & $\begin{array}{l}\text { Memiliki satu atribut berupa Process Performance. } \\
\text { Pada level ini proses telah diimplementasikan dan dapat } \\
\text { mencapai tujuan yang direncanakan. } \\
\text { (Prosesnya diimplementasikan). }\end{array}$ \\
\hline 2 & Managed & $\begin{array}{l}\text { Memiliki dua atribut berupa Performance Management dan } \\
\text { Work Product Management. } \\
\text { (Proses diimplementasikan dg direncakan, dimonitor dan } \\
\text { disesuaikan, terdapat pengaturan produk kerja). }\end{array}$ \\
\hline 4 & Predictable & $\begin{array}{l}\text { Memiliki dua atribut yaitu berupa Process Definition dan } \\
\text { Process Deployment. } \\
\text { (Proses ditetapkan dan diimplementasikan). }\end{array}$ \\
\hline 5 & Optimized & $\begin{array}{l}\text { Memilibut Control. } \\
\text { (Proses diukur dan dikendalikan). } \\
\text { Optimatization. } \\
\text { (Proses inovasi/optimasi/perbaikan berkelanjutan). }\end{array}$ \\
\hline
\end{tabular}

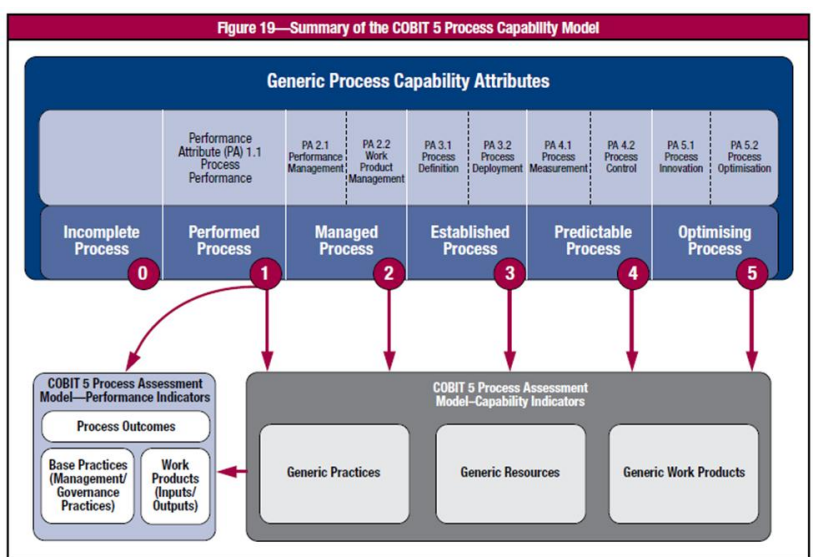

Gambar 2. Ringkasan COBIT 5 Process Capability Model 


\section{2 Metodologi Penelitian}

Penelitian ini menggunakan metode kualitatif yaitu dilakukan dalam kondisi ilmiah menggunakan human instrument. Tujuan pada penelitian ini berdasarkan jenis penelitian yaitu jenis penelitian deskriptif untuk melakukan evaluasi dengan Maturity Level berdasarkan COBIT 5 pada tahapan ujicoba Regulasi Sandbox OJK klaster aggregator.

Metode pengumpulan data yang dilakukan yaitu menggunakan wawancara terstruktur kepada narasumber OJK unit Groub Inovasi Keuangan Digital. Sampel yang digunakan pada penelitian ini berdasarkan klaster aggregator yang telah disahkan oleh forum panel sebagai prototype. Sampel yang digunakan yaitu cermati.com dan lifepal. Uji keabsahan data pada penelitian ini menggunakan validitas internal dengan metode triangulasi sumber untuk mengecek beberapa data yang diperoleh berdasarkan hasil wawancara dengan dokumen yang ada. Dan triangulasi waktu dengan melakukan wawancara pada waktu yang berbeda untuk menghasilkan data yang akurat. Teknik analisis data yang di gunakan adalah melakukan evaluasi dengan Maturity Level COBIT 5 berdasarkan hasil wawancara dihitung dan dianalisis berdasarkan maturity level COBIT 5 pada Tabel 1. Dimana hasil akan menunjukan tingkat maturity level kemampuan saat ini (current) dan tingkat maturity level yang diharapkan (expected). Setelah dilakukan perhitungan, maka langkah selanjutnya menentukan gap analysis untuk menganalisis interpretasi saat ini dan yang diharapkan serta memberikan rekomendasi dan perbaikan yang dilakukukan untuk mengatasi kesenjangan tersebut.

Teknik analisis data menggunakan evaluasi tingkat kematangan atau maturity level berdasarkan COBIT 5 pada Regulasi Sandbox dan COBIT 5 yang diambil pada domain Deliver, Service and Support yaitu pada subdomain manage problem dan manage business process control hal ini dikarenakan subdomain tersebut tujuan dan fungsinya sesuai pada item pengujian Regulasi Sandbox.

Manage Problem digunakan untuk mengidentifikasi serta mengklasifikasikan masalah dan menelusuri akar penyebab masalah guna memberikan penyelesaian secara tepat waktu agar masalah yang terjadi tidak berulang [18]. Berikut teknik analisis menggunakan COBIT 5 domain manage problem.

Tabel 2. COBIT 5 Subdomain DSS03 Manage Problem

\begin{tabular}{|l|c|}
\hline \multicolumn{1}{|c|}{ Management Practice } & Maturity Level \\
\hline DSS03.01 Identify and classify problems. & $0-5$ \\
\hline DSS03.02 Investigate and diagnose problems. & $0-5$ \\
\hline DSS03.03 Raise known errors. & $0-5$ \\
\hline DSS03.04 Resolve and close problems. & $0-5$ \\
\hline DSS03.05 Perform proactive problem management. & $0-5$ \\
\hline
\end{tabular}

Manage Business Process Control digunakan untuk menentukan dan melakukan kontrol bisnis secara tepat untuk memastikan bahwa informasi yang di proses telah memenuhi seluruh persyaratan yang ditentukan [19]. Berikut teknik analisis menggunakan COBIT 5 domain manage business process control.

Tabel 3. COBIT 5 Subdomain DSS06 Manage Business Control

\begin{tabular}{|l|c|}
\hline \multicolumn{1}{|c|}{ Management Practice } & Maturity Level \\
\hline $\begin{array}{l}\text { DSS06.01 Align control activities embedded in } \\
\text { business processes with enterprise objectives. }\end{array}$ & $0-5$ \\
\hline DSS06.02 Control the processing of information. & $0-5$ \\
\hline $\begin{array}{l}\text { DSS06.03 Manage roles, responsibilities, access } \\
\text { privileges and levels of authority. }\end{array}$ & $0-5$ \\
\hline
\end{tabular}

Lelasari, et., al [Pengukuran Maturity Level Cobit 5 dan Domain DSS (Deliver, Service, and Support) pada Regulasi Sandbox OJK Klaster Aggregator] 


\begin{tabular}{|l|c|}
\hline DSS06.04 Manage errors and exceptions. & $0-5$ \\
\hline $\begin{array}{l}\text { DSS06.05 Ensure traceability of Information events } \\
\text { and accountabilities. }\end{array}$ & $0-5$ \\
\hline DSS06.06 Secure information assets. & $0-5$ \\
\hline
\end{tabular}

\section{HASIL DAN PEMBAHASAN}

Berdasarkan hasil penelitian yang dilakukan pada ruang uji coba Regulasi Sandbox dimana ada beberapa tahapan yang dilakukan pada proses Regulasi Sandbox, diantaranya yaitu tahap pendalaman, tahap pengujian skenario, tahap pengujian dan percobaan, tahap perbaikan serta tahap penilaian yang diambil berdasarkan 2 sampel penyelenggara klaster aggregator yaitu cermati.com dan lifepal. Berdasarkan data yang diperoleh dari narasumber OJK bahwa penyelengga aggregator cermati.com dan lifepal secara keseluruhan telah melaksanakan uji coba Regulasi Sandbox berdasarkan 5 (lima) tahapan dan memiliki maturity level yang sama, namun pada tahap perbaikan terdapat perbedaan diantara sampel tersebut terkait hal penyelenggara cermati.com pernah melakukan sesuatu yang tidak sesuai dengan peraturan Otoritas Jasa Keuangan yang berlaku yaitu mengakses telefon yang tidak sesuai dengan ketentuan CAMILAN (camera, mickrofon and location). Sedangkan penyelenggara lifepal sudah mengikuti seluruh ketentuan yang berlaku. Namun, pada akhirnya cermati.com sudah memenuhi aturan yang ada pada seluruh tahapan Regulasi Sandbox. Berikut ditampilkan mengenai hasil aggregasi kedua sampel.

Tabel 4. Evaluasi Regulasi Sandbox Maturity Level dan COBIT 5

\begin{tabular}{|c|l|c|c|}
\hline No & Tahapan Regulasi Sandbox & $\begin{array}{c}\text { Hasil Evaluasi Current } \\
\text { Maturity Level }\end{array}$ & $\begin{array}{c}\text { Expected } \\
\text { Maturity Level }\end{array}$ \\
\hline 1 & Tahap Pendalaman & 4.2 & 5 \\
\hline 2 & Tahap Pengujian Skenario & 3 & 5 \\
\hline 3 & $\begin{array}{l}\text { Tahap Pengujian dan } \\
\text { Percobaan }\end{array}$ & 3.3 & 5 \\
\hline 4 & Tahap Perbaikan & 3.2 & 5 \\
\hline 5 & Tahap Penilaian & 2.9 & 5 \\
\hline
\end{tabular}

Tahap pendalaman yang terdiri dari beberapa item seperti penyelenggara yang telah mendapatkan penetapan sebagai prototype harus mempresentasikan (model bisnis, inovasi teknologi, proses bisnis, strategi manajemen risiko, rencana bisnis dan kesiapan operasional), data dan informasi tentang (profil penyelenggara, data dan unsur informasi tentang layanan, produk dan teknologi yang ditawarkan serta model bisnis yang akan diuji coba), manfaat yang ditawarkan bagi konsumen dan/atau perekonomian nasional, kerangka dan mekanisme kerja untuk penerapan perlindungan konsumen, hasil identifikasi potensi risiko dan upaya mitigasi risiko yang telah atau akan dilakukan, rencana yang akan dilakukan setelah uji coba dalam Regulasi Sandbox, data dan informasi disampaikan melalui surat elektronik dan melalui sistem elektronik, serta data dan informasi harus disampaikan kepada OJK selambat-lambatnya 5 (lima) hari kerja. Dimana keseluruhan item tersebut telah dievaluasi dengan hasil akhir sebesar 4.2 dimana berdasarkan maturity level tahapan pendalaman masuk dalam level 4 dengan value predictable yang artinya proses yang telah ditetapkan sebelumnya sekarang proses tersebut sudah diukur dan dikendalikan berdasarkan batasan-batasan yang yang ditentukan untuk mencapai hasil prosesnya. 
Tahap pengujian skenario yang terdiri dari beberapa item seperti pengujian dapat dilakukan dengan pendekatan melalui sistem elektronik dan/atau secara manual, prototype harus menyampaikan usulan skenario berupa uji coba (layanan, produk, teknologi, dan/atau model bisnis), aktivitas bisnis seperti (akuisisi konsumen, eksekusi transaksi, pelaporan dan lainnya) sesuai dengan model bisnis yang ada, pengujian akurasi dan error correction menggunakan data dummy, skenario pengujian manajemen risiko, perlindungan data dan konsumen, mitigasi risiko siber, pengujian terhadap aspek program anti pencucian uang dan pencegahan pendanaan terorisme. Dimana keseluruhan item tersebut telah dievaluasi dengan hasil akhir sebesar 3 dimana berdasarkan maturity level tahapan pendalaman masuk dalam level 3 dengan value established yang artinya proses nya telah ditetapkan dan diimplementasikan berdasarkan proses yang telah didefinisikan sebelumnya sehingga mampu mencapai hasil berdasarkan proses yang diinginkan.

Tahap pengujian dan percobaan yang terdiri dari beberapa item seperti pengujian dan percobaan legal dan tatakelola, model dan proses bisnis, teknologi informasi, manajemen risiko, perlindungan konsumen, rencana bisnis, anti pencucian uang dan pencegahan pendanaan terorisme, penyelenggara harus memiliki perangkat yang dapat meningkatkan efisiensi dan kepatuhan atas proses pemantauan yang akan dilakukan, seluruh proses Regulasi Sandbox dilaksanakan di OJK INFINITY, Otoritas Jasa Keuangan dapat melakukan observasi onsite ke pusat data dan/atau pusat pemulihan bencana penyelenggara, dan penyelenggara yang sudah melakukan kegiatan usaha dan sedang menjalani periode pengujian Regulasi Sandbox. Dimana keseluruhan item tersebut telah dievaluasi dengan hasil akhir 3.3 dimana berdasarkan maturity level tahapan pendalaman masuk dalam level 3 dengan value established yang artinya proses nya telah di tetapkan dan di implementasikan berdasarkan proses yang telah didefinisikan sebelumnya sehingga mampu mencapai hasil berdasarkan proses yang diinginkan.

Pada tahap perbaikan terdiri dari beberapa item seperti prototype melakukan perbaikan atas aspek pengujian, yang memenuhi kriteria potensi merugikan konsumen dan melakukan pelanggaran yang bertentangan dengan peraturan OJK, kewajiban melakukan perbaikan, perbaikan tidak melebihi jangka waktu pelaksanaan Regulasi Sandbox, permohonan perpanjangan jangka waktu perbaikan. Dimana keseluruhan item tersebut telah dievaluasi dengan hasil akhir 3.2 dimana berdasarkan maturity level tahapan pendalaman masuk dalam level 3 dengan value established yang artinya proses nya telah ditetapkan dan diimplementasikan berdasarkan proses yang telah didefinisikan sebelumnya sehingga mampu mencapai hasil berdasarkan proses yang diinginkan.

Tahap penilaian terdiri dari beberapa item seperti penilaian untuk memberikan kepastian status pada penyelenggara dinyatakan dengan tiga status berupa status direkomendasikan, perbaikan atau tidak direkomendasikan, menyampaikan penetapan hasil dari Regulasi Sandbox melalui surat, surat penetapan hasil Regulasi Sandbox dalam hal penyelenggara berstatus direkomendasikan (OJK memberikan rekomendasi pendaftaran sesuai dengan aktivitas usaha penyelenggara), dalam hal penyelenggara berstatus perbaikan (perpanjangan waktu paling lama 6 bulan setelah tanggal di tetapkan status perbaikan), permohonan perpanjangan jangka waktu paling lambat 1 bulan sebelum berakhirnya proses Regulasi Sandbox, dalam hal penyelenggara berstatus tidak direkomendasikan (tidak dapat mengajukan kembali IKD yang sama). Dimana keseluruhan item tersebut telah dievaluasi dengan hasil akhir 2.9 dimana berdasarkan maturity level tahapan penilaian masuk dalam level 1 dengan value managed yang artinya proses yang telah dijelaskan sebelumnya kemudian diimplementasikan dengan direncakan, dimonitor dan disesuaikan serta terdapat pengaturan produk kerja.

Hasil penelitian dengan menggunakan domain DSS (Deliver, Service and Support) pada COBIT 5 dengan subdomain yang digunakan yaitu DSS03 (Manage Problem) dan DSS06 (Manage Bussiness Process Control) untuk meningkatkan layanan informasi. Pemilihan domain 
manage problem dan manage business process control dengan pertimbangan subdomain tersebut tujuan dan fungsinya sesuai dengan item pada pengujian Regulasi Sandbox.

Tabel 5. Capability Level Sub Domian DSSO3 Manage Problem

\begin{tabular}{|c|l|c|c|}
\hline No & \multicolumn{1}{|c|}{ Sub Domain } & Current & Expected \\
\hline DSS03.01 & Identify and classify problems & 4 & 5 \\
\hline DSS03.02 & Investigate and diagnose problems & 4 & 5 \\
\hline DSS03.03 & Raise known errors & 4 & 5 \\
\hline DSS03.04 & Resolve and close problems & 4 & 5 \\
\hline DSS03.05 & Perform proactive problem management & 3 & 5 \\
\hline
\end{tabular}

Pada subdomain manage problem tahapan Regulasi Sandbox berdasarkan DSS03.01 terkait identifikasi serta klasifikasi masalah telah dilakukan dengan menetapkan laporan berkala bulanan serta menerapkan kriteria dan prosedur pelaporan masalah, berdasarkan DSS03.02 mengenai penyelidikan dan diagnosa masalah dilakukan dengan analisa tim Groub Inovasi Keuangan Digital yang selanjutnya dibahas pada forum panel, selanjutnya berdasarkan DSS03.03 untuk mengetahui lebih dalam permasalahan yang terjadi maka OJK melakukan evaluasi pada penyelenggara aggregator apabila belum memenuhi kriteria yang ditetapkan pada tahapan Regulasi Sandbox, kemudian berdasarkan DSS03.04 untuk mengatasi dan menutup masalah yang terjadi terdapat tahap perbaikan untuk memenuhi aspek-aspek yang ditentukan oleh OJK apabila belum memenuhi kriteria maka akan diberikan waktu perpanjangan 6 bulan sejak penetapan status bagi penyelenggara dan meyampaikan kembali perbaikan yang dimintakan OJK. Serta berdasarkan DSS03.05 dalam melakukan manajemen secara proaktif, OJK melakukan pengumpulan data dan menganalisis data operasional pada saat tahap pencatatan serta penyelenggara wajib melampirkan dokumen strategi manajemen risiko sehingga dapat digunakan untuk mengidentifikasi kemungkinan risiko yang akan terjadi dengan memberikan solusi yang tepat guna pencapaian manajemen masalah secara proaktif. Secara keseluruhan, management practice pada subdomain manage problem sudah cukup baik dalam melakukan identifikasi dan mengklasifikasikan masalah serta upaya pengendalian masalah yang mungkin akan terjadi pada tahapan Regulasi Sandbox. Dimana beberapa item management practice pada subdomain manage problem prosesnya telah memenuhi atribut process measurement dan process control yang artinya masuk pada level 4 dengan value predivtable dimana prosesnya telah diukur dan dikendalikan. Namun, dalam melakukan manajemen secara proactive pada tahapan regulasi sandbox, prosenya masuk pada level 3 dengan value established artinya prosesnya telah ditetapkan dan diimplementasikan.

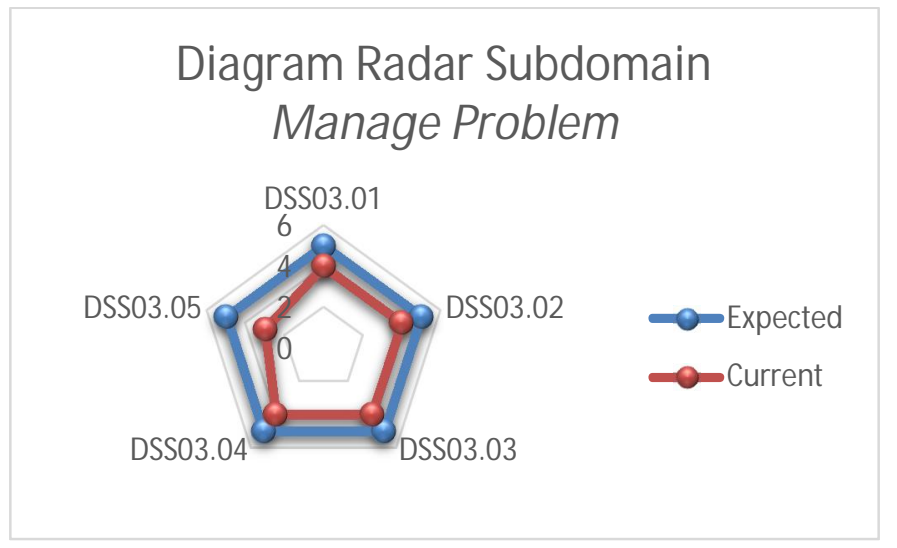

Gambar 3. Diagram Radar Subdomain Manage Problem 
Tabel 6. Capability Level Sub Domian DSS03 Manage Business Process Control

\begin{tabular}{|c|c|c|c|}
\hline No & Sub Domain & Current & Expected \\
\hline DSS06.01 & $\begin{array}{l}\text { Align control activities embedded in } \\
\text { business processes with enterprise } \\
\text { objectives }\end{array}$ & 3 & 5 \\
\hline DSS06.02 & Control the processing of information & 3 & 5 \\
\hline DSS06.03 & $\begin{array}{l}\text { Manage roles, responsibilities, access } \\
\text { privileges and levels of authority }\end{array}$ & 4 & 5 \\
\hline DSS06.04 & Manage errors and exceptions & 3 & 5 \\
\hline DSS06.05 & $\begin{array}{l}\text { Ensure traceability of Information events } \\
\text { and accountabilities }\end{array}$ & 3 & 5 \\
\hline DSS06.06 & Secure information assets & 4 & 5 \\
\hline
\end{tabular}

Pada subdomain manage business process control dimana berdasarkan DSS06.01 untuk melakukan penyesuaian pengaturan aktivitas yang ada dalam bisnis proses dengan kebutuhan perusahaan, OJK melakukan pemantauan dan menilai pelaksanaan aktivitas proses Regulasi Sandbox melalui forum panel, berdasarkan DSS06.02 dalam melakukan pengontrolan proses informasi, untuk memastikan bahwa keseluruhan data yang dibutuhkan pada saat proses Regulasi Sandbox aman, valid dan lengkap yaitu dengan cara OJK meminta hasil PEN TEST (penetration test) kepada penyelenggara klaster aggregator, sedangkan berdasarkan DSS06.03 peran OJK dalam mengelola peran dan tanggung jawab serta hak akses untuk mendukung pelaksanaan Regulasi Sandbox telah dilaksanakan dengan cara apabila diperlukan, OJK akan meminta keseluruhan data kepada penyelnggara aggregator dan menjamin kerahasiaan data tersebut. Berdasarkan DSS06.04 untuk mengelola dan meninjau kesalahan oleh penyelenggara pada saat proses Regulasi Sandbox dilakukan dengan memberikan surat peringatan kepada penyelenggara yang telah merujuk pada POJK 13.07/2013 pasal 39. Sedangkan berdasarkan DSS06.05 dalam menjamin keandalan seluruh informasi yang diberikan telah sesuai dengan tujuan yang telah ditetapkan pada Regulasi Sandbox, OJK melakukan uji coba keandalan informasi selanjutnya dianalisis pada forum panel. Selain itu juga berdasarkan DSS06.06 OJK juga telah menjamin keamanan asset informasi serta keamanan data dan privasi penyelenggara dengan memiliki kode etik terkait hak akses data dimana setiap anggota dewan komisioner, pejabat dan seluruh pegawai OJK wajib menjamin kerahasiaan data dan informasi terkait pelaksanaan tugas OJK untuk tidak melakukan pengungkapan informasi rahasia baik selama bekerja atau setalah tidak bekerja pada Otoritas Jasa Keuangan. Dimana OJK dalam melakukan identifikasi, mengelola dan mengoperasikan pengendalian informasi yang relevan beberapa prosesnya pada item management practice subdomain manage business process control telah memenuhi atribut process definition dan process deployment atau masuk pada level 3 dengan value established namun terkait item pada DSS06.03 dan DSS06.06 prosesnya telah memenuhi atribut process measurement dan process control dimana telah masuk pada level 4 dengan value predictable yang artinya prosesnya telah diukur dan dikendalikan. 


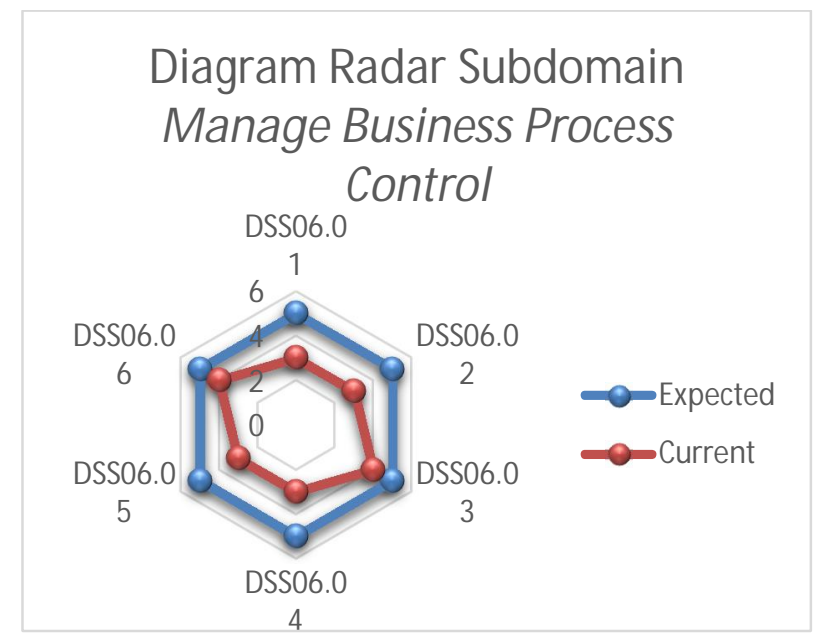

Gambar 4. Diagram Radar Subdomain Manage Business Process Control

\section{KESIMPULAN}

Berdasarkan penelitian yang telah dilakukan oleh peneliti mengenai uji Regulasi Sandbox OJK khususnya pada Inovasi Keuangan Digital klaster aggregator dengan sampel yang dipilih pada cermati.com dan lifepal maka dapat ditarik kesimpulan bahwa:

1. Klaster aggregator berdasarkan sampel yang dipilih telah sesuai dalam melaksanakan tahapan pada pengujian Regulasi Sandbox dengan mengikuti 5 (lima) tahapan yang dilakukan seperti: tahap pendalaman, tahap pengujian skenario, tahap pengujian dan percobaan, tahap perbaikan dan tahap penilaian.

2. Tingkat kematangan sampel penyelenggara aggregator berdasarkan Regulasi Sandbox yang diukur menggunakan maturity level COBIT 5 yaitu:

a. Tahap pendalaman berdasarkan hasil evaluasi diperoleh nilai maturity level sebanyak 4.2 yang artinya masuk pada value predictable.

b. Tahap pengujian skenario berdasarkan hasil evaluasi diperoleh nilai maturity level sebanyak 3 yang artinya masuk pada value established.

c. Tahap pengujian dan percobaan berdasarkan hasil evaluasi diperoleh nilai maturity level sebanyak 3.3 yang artinya masuk pada value established

d. Tahap perbaikan berdasarkan hasil evaluasi diperoleh nilai maturity level sebanyak 3.2 yang artinya masuk pada value established

e. Tahap penilaian berdasarkan hasil evaluasi diperoleh nilai maturity level sebanyak 2.9 yang artinya masuk pada value managed.

3. Domain manage problem dan domain manage business process control berdasarkan COBIT 5 telah diimplementasikan pada saat pengujian Regulasi sandbox pada klaster aggregator dimana tujuan dan fungsinya sesuai dengan item pada pengujian Regulasi Sandbox.

4. Tingkat kematangan atau maturity level domain manage problem berdasarkan hasil evaluasi yang telah dilakukan sebesar 3.8 yang artinya dalam maturity level masuk pada value predictable secara keseluruhan prosesnya telah diukur dan dikendalikan. Sedangkan tingkat kematangan atau maturity level domain manage business process control berdasarkan hasil evaluasi yang telah dilakukan sebesar 3.33 yang artinya dalam maturity level masuk pada value established secara keseluruhan prosesnya telah ditetapkan dan diimplementasikan. 


\section{SARAN}

Berikut saran yang diberikan peneliti berdasarkan hasil penelitian mengenai analisis Regulasi Sandbox OJK klaster aggregator berdasarkan maturity level dan COBIT 5:

1. Saran untuk peneliti selanjutnya dikarenakan keterbatasan waktu dan resources pada penelitian ini, maka diharapkan untuk peneliti selanjutnya dapat membahas lebih lengkap pada domain lain yang memiliki korelasi pada keseluruhan item yang ada pada tahapan Regulasi Sandbox.

2. Saran untuk OJK perlu peningkatan pada tahapan penilaian karena memiliki nilai maturity level paling kecil dari seluruh tahapan yang ada sehingga pengujian Regulasi Sandbox memenuhi target serta menghasilkan produk IKD yang berkualitas dan sesuai tujuan Regulasi Sandbox untuk menciptakan platform aggregator yang memberikan perlindungan bagi konsumen, bagi calon pengguna, memberikan kepastian status bagi penyelenggara fintech aggregator agar dapat menjalankan usahanya sesuai dengan peraturan yang berlaku dan tidak melanggar aturan yang telah ditetapkan pada Otoritas Jasa Keuangan.

3. Saran untuk masyarakat harus lebih hati-hati dan waspada dalam memilih produk finansial teknologi yang tepat, tentunya harus mengecek terlebih dahulu apakah produk finansial tersebut sudah terdaftar atau diawasi oleh Otoritas Jasa Keuangan atau belum sehingga nantinya tidak ada pihak yang dirugikan.

\section{UCAPAN TERIMA KASIH}

Penulis mengucapkan terimakasih kepada LPPM Universitas Telkom yang sudah mensupport dana dalam penelitian ini dan Universitas Telkom yang telah memberikan akses ke paper hasil penelitian melalui Open Library ke Universitas Telkom dan Bapak Bintang Prabowo, Ibu Zahrin Haznina Qolby, Ibu Kurniatul Khasanah dan seluruh staf Groub Inovasi Keuangan Digital OJK baik sebagai narasumber maupun dalam meluangkan waktunya disaat kesibukan aktivitas pekerjaan yang begitu padat.

\section{DAFTAR PUSTAKA}

[1] I. Adhitya Wulanata Chrismastianto. 2017, "Analisis SWOT Implementasi Teknologi Finansial Terhadap Kualitas Layanan Perbankan Di Indonesia,” J. Ekon. dan Bisnis, Vol. 20, No. 1, pp. 133-144.

[2] L. D'Alimonte et al. 2014, "Does Prostate Biopsy After HDR Brachytherapy Have Any Clinical Significance?,” J. Med. Imaging Radiat. Sci., Vol. 45, No. 2, pp. 176-177, , doi: 10.1016/j.jmir.2014.03.053.

[3] Statista. 2017, “Transaksi Fintech Indonesia 2015-2021," [Online]. Available: https://databoks.katadata.co.id/.

[4] Maizal Walfajri and H. K. Dewi. 2020, "Mulai Berkembang Tahun 2016, Begini Kondisi Fintech Indonesia Hingga Kuartal II-2020," [Online]. Available: https://keuangan.kontan.co.id/. 
[5] L. Widyastuti and A. Yunita. 2020, "IJAB: Indonesian Journal of Accounting and Business Analisis Penerimaan Teknologi Financial Intention Melalui Pendekatan Teori Perilaku Rencanaan (Theory of Planned Behavior Atau Tpb) (Studi pada Masyarakat Kota Pangkalpinang),” Vol. 1, No. 2, pp. 131-152.

[6] K. Khassanah. 2020, “Otoritas Jasa Keuangan,”

[7] R. D. Pambudi. 2019, "Perkembangan Fintech Di Kalangan Mahasiswa UIN Walisongo," Harmony, Vol. 4, No. 2, pp. 74-81.

[8] Yasmine Maghfira and A. Husaini. 2019, “OJK Bakal Buat Peraturan Soal Fintech Aggregator Semacam Cermati.com," [Online]. Available: https://keuangan.kontan.co.id/news/ojk-bakal-buat-peraturan-soal-fintech-aggregatorsemacam-cermaticom.

[9] D. Komisioner and O. Jasa. 2015, “Otoritas Jasa Keuangan Republik Indonesia.”

[10] Otoritas Jasa Keuangan. 2019, "Salinan Surat Edaran Otoritas Jasa Keuangan Indonesia Nomor 21/SEOJK.02/2019 Tentang Regulatory Sandbox.”

[11] Otoritas Jasa Keuangan (OJK). 2017, “Ruang Uji Coba Terbatas (Regulatory Sandbox) Teknologi Finansial (Space For Limited Trial (Regulatory Sandbox) of Financial Technology)."

[12] J. J. Goo and J. Y. Heo. 2020, "The Impact of The Regulatory Sandbox On The Fintech Industry, With A Discussion On The Relation Between Regulatory Sandboxes and Open Innovation," J. Open Innov. Technol. Mark. Complex., Vol. 6, No. 2, doi: 10.3390/JOITMC6020043.

[13] L. N. Amali, M. R. Katili, S. Suhada, and L. Hadjaratie. 2020, "The Measurement of Maturity Level of Information Technology Service Based on COBIT 5 Framework," Vol. 18, No. 1, pp. 133-139, doi: 10.12928/TELKOMNIKA.v18i1.10582.

[14] M. N. Rizal, S. Mukaromah, and D. Ridwandono. 2020, "Analisis Maturity Level Menggunakan Stanfar Cobit 4.1 pada Instalasi SIM Rumah Sakit Umum Haji Surabaya," J. Inform. dan Sist. Inf., Vol. 1, No. 1, pp. 67-73.

[15] J. M. Hartono and W. Abdillah. 2011, "Sistem Tatakelola Teknologi Informasi, Andi., Yogyakarta.

[16] A. K. Darmawan and A. Dwiharto. 2019, "Pengukuran Capability Level Kualitas Layanan E-Government Kabupaten Pamekasan Menggunakan Framework COBIT 5.0," INTENSIF J. Ilm. Penelit. dan Penerapan Teknol. Sist. Inf., Vol. 3, No. 2, p. 93, doi: 10.29407/intensif.v3i2.12659.

[17] N. Steven, F. Messakh, A. R. Tanaamah, and M. Cs. 2021, "Analisis Sistem Informasi Berbasis Cobit 5 (Studi Kasus: LTC UKSW),” Vol. 8, No. 1, pp. 388-400. 